OPEN ACCESS

Edited by:

Trinidad Montero-Melendez,

Queen Mary University of London, United Kingdom

Reviewed by:

Vincenzo Brancaleone

University of Basilicata, Italy Jianmin Chen,

Queen Mary University of London, United Kingdom

${ }^{*}$ Correspondence: Magnus Bäck

Magnus.Back@ki.se

Specialty section: This article was submitted to Inflammation Pharmacology,

a section of the journal

Frontiers in Pharmacology

Received: 27 July 2018

Accepted: 18 October 2018

Published: 14 November 2018

Citation:

Pirault J and Bäck M (2018) Lipoxin and Resolvin Receptors

Transducing the Resolution

of Inflammation in Cardiovascular Disease. Front. Pharmacol. 9:1273.

doi: 10.3389/fphar.2018.01273

\section{Lipoxin and Resolvin Receptors Transducing the Resolution of Inflammation in Cardiovascular Disease}

\author{
John Pirault ${ }^{1,2}$ and Magnus Bäck ${ }^{1,2,3 *}$ \\ 'AGing Innovation \& Research (AGIR) Program at INSERM U1116, Nancy University Hospital and The University of Lorraine, \\ Nancy, France, ${ }^{2}$ Center for Molecular Medicine, Karolinska Institutet, Stockholm, Sweden, ${ }^{3}$ Division of Valvular \\ and Coronary Disease, Karolinska University Hospital, Stockholm, Sweden
}

A non-resolving inflammation results in a chronic inflammatory response, characteristic of atherosclerosis, abdominal aortic aneurysms and several other cardiovascular diseases. Restoring the levels of specialized proresolving mediators to drive the chronic cardiovascular inflammation toward resolution is emerging as a novel therapeutic principle. The lipid mediators lipoxins and resolvins exert their proresolving actions through specific G-protein coupled receptors (GPCR). So far, four GPCR have been identified as the receptors for lipoxin A4 and the D- and E-series of resolvins, namely ALX/FPR2, DRV1/GPR32, DRV2/GPR18, and ERV1/ChemR23. At the same time, other pro-inflammatory ligands also activate some of these receptors. Recent studies of genetic targeting of these receptors in atherosclerotic mouse strains have revealed a major role for proresolving receptors in atherosclerosis. The present review addresses the complex pharmacology of these four proresolving GPCRs with focus on their therapeutic implications and opportunities for inducing the resolution of inflammation in cardiovascular disease.

Keywords: atherosclerosis, ChemR23, FPR2, inflammation, lipoxygenase

\section{INTRODUCTION}

A non-resolving inflammation constitutes the foundation of chronic inflammation, a key characteristic of several cardiovascular diseases (Serhan, 2014; Perretti et al., 2015). For example, the role of inflammation in atherosclerosis has been widely recognized and anti-inflammatory treatments are currently emerging to prevent coronary and cerebral atherosclerotic events (Bäck and Hansson, 2015). Indeed, the chronic inflammation observed within atherosclerotic lesions is consistent with a failure in the resolution of inflammation (Fredman and Tabas, 2017). Likewise, the inflammatory response induced by acute ischemia necessitates a functioning resolution for adequate healing after for example myocardial infarction (Kain et al., 2014).

Prostaglandins and leukotrienes are formed from arachidonic acid through the cyclooxygenase (COX) and 5-lipoxygenase (5-LO) enzymatic pathways, respectively. Temporal analysis of the response to tumor necrosis factor (TNF) $\alpha$ injection in the murine air pouch model revealed that the appearance of these lipid mediators coincided with neutrophil infiltration in the early acute inflammatory response (Levy et al., 2001). However, during the resolution phase, there was a 
lipid mediator class switch from predominantly 5-LO-derived leukotriene $\mathrm{B}_{4}\left(\mathrm{LTB}_{4}\right)$ to lipoxin $\mathrm{A}_{4}\left(\mathrm{LXA}_{4}\right)$. In the latter study, this switch was shown to coincide with an upregulation of the 15-LO enzyme, allowing dual lipoxygenation of arachidonic acid into $\mathrm{LXA}_{4}$ by 15-LO and 5-LO (Levy et al., 2001). $\mathrm{LXA}_{4}$ can in addition be formed through sequential actions of 5-LO and 12-LO and also from 5-LO metabolism of an arachidonic acid product from acetylated COX-2. The latter biosynthetic pathways generates a more stable 15-R-epimer of $\mathrm{LXA}_{4}$, also referred to as aspirin-triggered $\mathrm{LXA}_{4}$ (ATL) since the acetylation of COX-2 requires acetylsalicylic acid (Serhan, 2014). In coronary arteries, $\mathrm{LXA}_{4}$ levels increase after aspirin treatment (Brezinski et al., 1992). Resolvin (Rv) is another class of proresolving lipid mediators, which are formed from LO metabolism of omega-3 essential polyunsaturated fatty acids, with the D-series resolvins (e.g., RvD1, RVD2, RvD3...) being derived from docosahexaenoic acid (DHA), whereas the E-series resolvins (RvE1 and RvE2) are formed from eicosapentaenoic acid (EPA) (Serhan, 2014). Likewise with the formation of ATL, aspirintriggered forms of these mediators (AT-Rv) also exist.

The proresolving response to these different lipid mediators is transduced by specific receptors, which belongs to the 7 transmembrane G-protein coupled (GPCR) family of receptors (Cash et al., 2014). So far, four receptors for proresolving lipid mediators have been identified as depicted in Figure 1. The aim of the present review is to address the complex pharmacology of these four GPCRs with focus on their therapeutic implications and opportunities for inducing the resolution of inflammation in cardiovascular disease.

\section{ALX/FPR2}

\section{ALX/FPR2 Ligands}

The A lipoxin and formyl peptide receptor 2 (ALX/FPR2) possesses a high sequence homology (70\%) to the formyl peptide receptors (FPR) (Chiang et al., 2006). ALX/FPR2 ligates the lipid mediators $\mathrm{LXA}_{4}$ (Gronert et al., 1998; Krishnamoorthy et al., 2010), aspirin-triggered LX (ATL)(Chiang et al., 2000; Dalli et al., 2013a), Resolvin $\mathrm{D}_{1}$ (RvD1) (Krishnamoorthy et al., 2012), and Resolvin D3 (Arnardottir et al., 2016) as well as the annexin A1 protein (Hayhoe et al., 2006) to transduce their pro-resolving effects (Figure 2). Those include limiting leukocyte trafficking and activation both in vitro and in vivo (Hachicha et al., 1999) as well as stimulating efferocytosis (Maderna et al., 2010), granulocyte apoptosis (Barnig et al., 2013), and leukocyte egress (van Gils et al., 2012). It should however, be taken into consideration that ALX/FPR2 in addition is activated by amyloidogenic and anti-bacterial peptides (Ye et al., 2009), which induces pro-inflammatory signaling through the same receptor (Figure 2). One of the downstream ALX/FPR2 signaling events that transduce its proresolving effects is the suppression of calcium-sensing kinase calcium-calmodulindependent protein kinase and subsequent inhibition of p38 mitogen-activated protein kinase (MAPK) phosphorylation in murine bone marrow-derived cells (Fredman et al., 2014; Petri et al., 2018).

\section{Neutrophil ALX/FPR2 Signaling in Ischemia Reperfusion and Abdominal Aortic Aneurysms}

ALX/FPR plays a major role in granulocyte turnover during the resolution of inflammation (Hachicha et al., 1999). This is for example well recognized in models of ischemia and reperfusion, in which lipoxin signaling acts to limit leukocyte trafficking (Chiang et al., 1999; Smith et al., 2015). Consequently, mice lacking the murine homolog of ALX/FPR2 exhibit an exacerbated inflammatory response following for example mesenteric (Brancaleone et al., 2013) and cerebral (Vital et al., 2016) ischemia and reperfusion. ALX/FPR2 is also upregulated during myocardial ischemia, and its ligands limit myocardial necrosis and inflammation after coronary ligation (Kain et al., 2015; Halade et al., 2018). The protective effects of the latter studies are centered on a neutrophil response, both in terms of neutrophils being the major source of $\mathrm{LXA}_{4}$ production during ischemia and that ALX/FPR2 signaling limits the neutrophil adherence and infiltration into the ischemic area (Brancaleone et al., 2013; Vital et al., 2016).

Abdominal aortic aneurysm (AAA) is characterized by a progressive aortic dilatation and weakening of the vascular wall that may provoke an aortic rupture, which most commonly is fatal (Michel et al., 2011; Bäck et al., 2013). Neutrophil chemoattractants and neutrophil-derived proteolytic enzymes are closely related to AAA expansion and those findings have underlined the key role of neutrophils in this disease (Houard et al., 2009a,b; Umeda et al., 2011). A recent mass spectrometry lipidomics analysis revealed that the ALX/FPR2 ligands $\mathrm{LXA}_{4}$, ATL, and RvD1 are increased in patients undergoing surgical AAA repair (Pillai et al., 2012). In addition, D-series resolvins inhibit aortic dilatation in experimental murine models of AAA (Pope et al., 2016). The latter findings were recently shown to be largely attributed to a limited neutrophil inflammation. ALX/FPR2 deficiency enhances AAAs and increases aneurysmal leukocyte infiltration in response to angiotensin II-infusion in hyperlipidemic ApoE ${ }^{-/-}$mice (Petri et al., 2018). Disrupting lipoxin and resolvin formation by genetic deletion of 12/15-LO mimics those effects (Petri et al., 2018), hence reinforcing the protective role of lipoxin formation and ALX/FPR2 signaling in AAA. The extrapolation of those observations to human AAA is supported by the significant correlation between ALX/FPR2 and neutrophil markers, and the significant down-regulation of FPR2 in the adventitia of aneurysmal versus healthy human aortae (Petri et al., 2018).

\section{ALX/FPR2 and Macrophage-Responses in Atherosclerosis}

ALX/FPR2 has been identified in macrophages in human atherosclerotic lesions (Petri et al., 2015a). However, genetic targeting of ALX/FPR2 has generated conflicting results in different hyperlipidemic murine models. In both $\mathrm{LDLR}^{-/-}$and $\mathrm{ApoE}^{-/-}$mice, genetic disruption of the murine homolog of ALX/FPR2 results in reduced atherosclerosis (Petri et al., 2015a, Petri et al., 2017). However, another study reported increased lesion size in early stages of atherosclerosis in ApoE and 
ARACHIDONIC ACID

(AA)

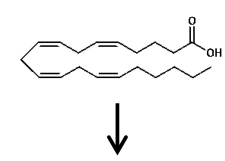

Lipoxin $\mathrm{A}_{4}$

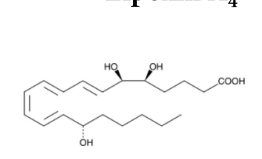

ynn

AIXIPR2

unut
DOCOSAHEXAENOIC ACID

(DHA)

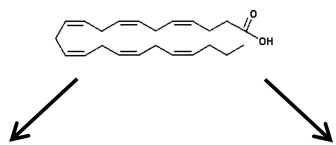

Resolvin D1

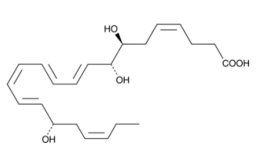

Yronn

DRV1/GPR32

UVU

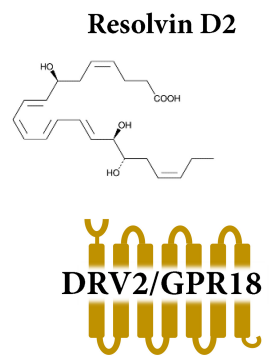

EICOSAPENTANOIC ACID

(EPA)
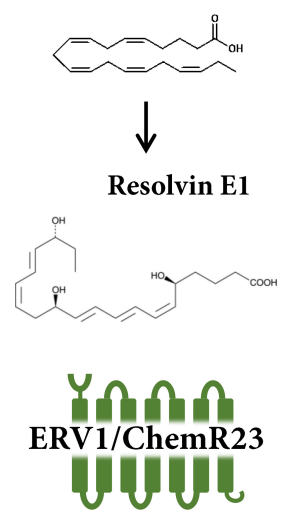

FIGURE 1 | Receptors and ligands for lipoxin and resolvin receptors. Lipoxin $A_{4}$ is derived from arachidonic acid, whereas $D$ - and E- series resolvins are formed from metabolism of the omega-3 polyunsaturated fatty acids docosahexaenoic acid (DHA) and eicosapentaenoic acid (EPA), respectively. There are currently four known lipoxin and resolvin receptors; ALX/FPR2 for lipoxin $A_{4}$ and resolvin D1; DRV1/GPR32 for resolvin D1; DRV2/GPR18 for resolvin D2; and ERV1/ChemR23 for resolvin E1.

ALX/FPR2 double-knock-out mice (Drechsler et al., 2015). Likewise, transplantation of ALX/FPR2-deficient bone marrow into lethally irradiated $\mathrm{LDLR}^{-/-}$mice has been reported to exert either protective (Petri et al., 2015a) or neutral (Fredman et al., 2015) effects on atherosclerotic lesion size.

One possible reason for these apparent differences may be a different balance between pro-inflammatory and proresolving ALX/FPR2 agonists in the different models used (Bäck et al., 2015). As mentioned above, also pro-inflammatory ligands activate ALX/FPR2 and appear to be dominant in some atherosclerotic mouse models (Petri et al., 2015a). For example, the circulating levels of pro-inflammatory ALX/FPR2 ligand serum amyloid A (SAA) is approximately 10,000-fold higher compared with $\mathrm{LXA}_{4}$ in $\mathrm{LDLR}^{-/-}$mice. Furthermore, ALX/FPR2 is activated by the anti-microbial cathelicidin LL-37, which is up-regulated in human atherosclerotic lesions (Edfeldt et al., 2006), and genetic targeting of its murine homolog, the cathelicidin-related anti-microbial peptide (CRAMP), reduces atherosclerosis burden (Doring et al., 2012). Taken together, those findings indicate a failure in the resolution of inflammation in atherosclerosis manifested by a disturbed balance between ALX/FPR2 ligands, with decreased levels of proresolving agonists and increased levels of pro-inflammatory agonists, as depicted in Figure 2. In support of the latter notion, delivery of either ATL (Petri et al., 2017) or nanoparticles containing the annexin A1 mimicking peptide Ac2-26 (Fredman et al., 2015) reduces experimental atherosclerosis. Those effects are however not observed in absence of a functional ALX/FPR2, hence reinforcing the importance of this receptor in transducing the resolution of inflammation in response to appropriate ligand stimulation. These findings also indicate that stimulating proresolving signaling through ALX/FPR2 may be a therapeutic option for atherosclerosis.

Atherosclerotic lesions derived from ATL-treated ApoE mice exhibit a decreased macrophage content and less inflammation
(Petri et al., 2017), consistent with the lipoxin-induced reduction of proi-nflammatory cytokines observed in monocytic cells in vitro (Petri et al., 2015c). Furthermore, less apoptotic cells are observed in atherosclerotic lesions after ATL treatment (Petri et al., 2017). Indeed, $\mathrm{LXA}_{4}$ and Ac2-26 stimulate efferocytosis in bone marrow-derived macrophages (BMDM), whereas BMDMs derived from ALX/FPR2 knock-out mice do not increase efferocytosis in response to these agonists (Maderna et al., 2010).

\section{FPR2/ALX in Smooth Muscle Cells and Intimal Hyperplasia}

In addition to inflammatory cells, also vascular smooth muscle cells in the atherosclerotic lesion express ALX/FPR2 (Petri et al., 2015a). In vitro, the ALX/FPR2 agonists ATL and AT-RvD1 inhibit migration of human venous SMCs (Ho et al., 2010; Miyahara et al., 2013), an effect which has been replicated for ATL in murine SMCs and shown to be blunted by genetic ALX/FPR2 disruption (Petri et al., 2015b). The mechanism involves direct effects on actin polymerization and focal adhesion formation in SMCs through the cAMP/protein kinase A pathway (Mottola et al., 2017).

Importantly, lipoxins are produced during percutaneous coronary interventions (PCI) and the administration of proresolving lipid mediators reduces intimal hyperplasia in different murine models of vascular injury (Miyahara et al., 2013; Akagi et al., 2015; Petri et al., 2015b; Liu et al., 2018a). The protective effect of ATL on intimal hyperplasia is however not observed in ALX/FPR2 knock-out mice (Petri et al., 2015b). Although treatment with cell cycle inhibitors by means of drug eluting stents has reduced the occurrence of restenosis after PCI, intimal hyperplasia remains a significant clinical problem in for example coronary artery bypass graft failure (Wadey et al., 2018) and could hence represent an additional therapeutic potential for ALX/FPR2 ligands. 


\section{proresolving: $\mathrm{LXA}_{4} / \mathrm{ATL} / \mathrm{RvD1} / \mathrm{RvD3} /$ annexin A1/Ac2-26}

proinflammatory: SAA/cathelicidin LL-37

\section{ALX/FPR2}

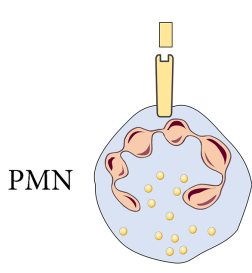

$\downarrow$ infiltration $\downarrow$ adherence $\downarrow$ p38 MAPK $\downarrow$ inflammation $\downarrow$ pro-inflammatory cytokines $\downarrow$ p38 MAPK

$\uparrow$ efferocytosis
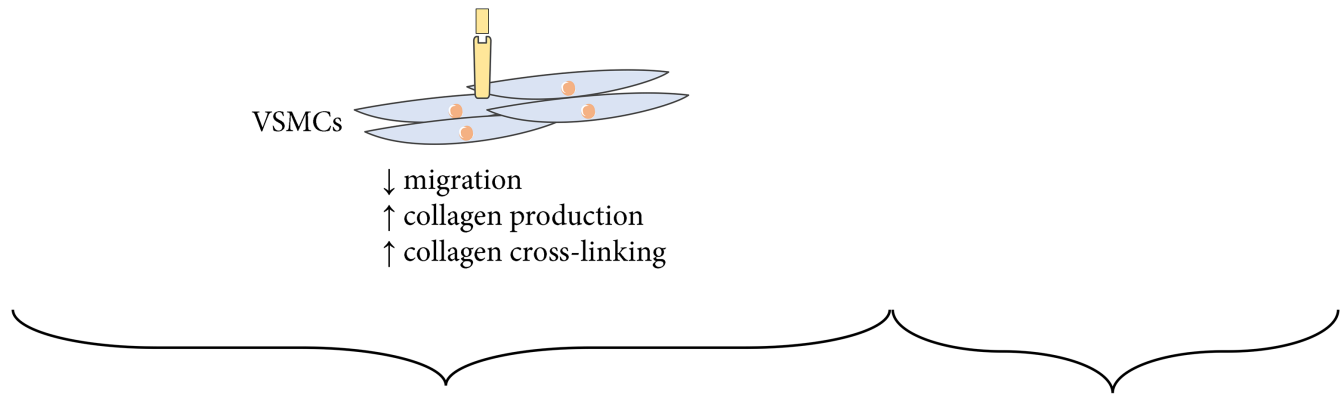

$\downarrow$ inflammation

$\uparrow$ inflammation

$\downarrow$ atherosclerosis

$\uparrow$ atherosclerosis

FIGURE 2 | Proresolving and pro-inflammatory ligands for the ALX/FPR2 receptor. The proresolving ligands lipoxin $A_{4}\left(L X A_{4}\right)$, aspirin-triggered $L X A_{4}$ (ATL), resolvin (Rv) D1, annexin A1 and the annexin-derived peptide Ac2-26 transduce proresolving signaling to inhibit atherosclerosis. On the other hand, other classes of ligands including $\mathrm{N}$-formylated peptides serum amyloid A (SAA) and the cathelicidin LL-37/mCRAMP (mouse cathelicidin-related anti-microbial peptide) signal pro-inflammation and increase atherosclerosis through the same receptor. PMN, polymorphonuclear neutrophil granulocytes; VSMCs, vascular smooth muscle cells; MAPK, mitogen-activated protein kinase.

In addition to intimal hyperplasia, direct effects of ALX/FPR2 signaling in SMCs may also be involved in extracellular matrix remodeling, with implications for atherosclerotic plaque stability and aneurysm formation. For example, SMCs lacking ALX/FPR2 exhibit a decreased collagen production and cross-linking, whereas collagenases are increased, accompanied by decreased collagen content in atherosclerotic and aneurysmal lesions in hyperlipidemic mice lacking FPR2/ALX (Petri et al., 2015a, Petri et al., 2018).

\section{ALX/FPR2: Therapeutic Options for Cardiovascular Disease}

The above-mentioned studies support that proresolving lipid mediator signaling through ALX/FPR2 exert beneficial effects with implications for several cardiovascular diseases. The chronic inflammatory reactions in atherosclerosis may be caused by a failure in the resolution of inflammation through a lack of production of proresolving lipid ALX/FPR2 ligands and an unmasking of pro-inflammatory ALX/FPR2 signaling (Figure 2).
Restoring the proresolving ALX/FPR2 signaling by means of lipid or peptide agonists may offer novel therapeutic options in not only the prevention of atherosclerosis progression but also to increase atherosclerotic plaque stability. Likewise, enhancing ALX/FPR2 signaling could be considered in vascular interventions both in the context of limiting neutrophil-mediated ischemia and reperfusion injury and SMC-mediated intimal hyperplasia and restenosis after different revascularization procedures.

\section{DRV1/GPR32}

\section{DRV1/GPR32 Ligands and Inflammatory Signaling}

In addition to ALX/FPR2, RvD1, and RvD3 also signal through the receptor DRV1/GPR32 (Krishnamoorthy et al., 2010; Dalli et al., 2013b), which is also activated by Resolvin D5 (RvD5) (Chiang et al., 2012) and stable endogenous 
(aspirin-triggered) and synthetic D-resolvin analogs (Orr et al., 2015). DRV1/GPR32 is expressed in human macrophages (Schmid et al., 2016) in which it increases phagocytosis (Chiang et al., 2012) and miRNAs involved in proresolving signaling (Recchiuti et al., 2011; Recchiuti and Serhan, 2012) in response to RvD1. Likewise, knocking down DRV1/GPR32 by means of small interfering (si) RNA blocks the RvD1-induced macrophage polarization toward a pro-resolution phenotype (Schmid et al., 2016). In addition to macrophage responses, D-resolvin signaling through DRV1/GPR32 also regulate adaptive immune circuits by preventing T cell differentiation toward Th1 and Th17, as well as promoting the generation of regulatory T-cells (Chiurchiu et al., 2016).

\section{DRV1/GPR32: Therapeutic Options for Cardiovascular Disease}

The reported actions of D-resolvin signaling through DRV1/GPR32 in macrophages and T-cells are consistent with beneficial actions in vascular inflammatory conditions. In addition, additional direct effects on the vascular wall can be anticipated since DRV1/GPR32 is also expressed on vascular endothelial (Chattopadhyay et al., 2017) and smooth muscle cells (Karagiannis et al., 2013). The protective effects of RvD1 on endothelial cell integrity and barrier function is blocked by either neutralizing antibodies against DRV1/GPR32 and ALX/FPR2 receptor antagonism, suggesting similar RvD1-induced signaling through these two receptors (Chattopadhyay et al., 2017).

However, comprehensive in vivo studies for determining the cardiovascular phenotypes are presently lacking, mainly since there is no murine homolog of the human DRV1/GPR32 receptor (Bäck et al., 2014).

\section{DRV2/GPR18}

\section{DRV2/GPR18 Ligands}

GPR18 was discovered as orphan receptor in the late 90s. Located on the distal part of the chromosome 14 in mice, with its homolog at locus 13q32 on chromosome 13 in humans (Samuelson et al., 1996; Gantz et al., 1997). The gene encodes an open reading frame of $993 \mathrm{bp}$ and transcripts were initially found to be most abundant in spleen and testis, although expression was also found in for example thymus, peripheral blood leukocytes, and brain (Vassilatis et al., 2003; Chiang et al., 2015). The identification of GRP18 as the receptor for RvD2 was made through a GPCR$\beta$-arrestin-based screening (Chiang et al., 2015), and the receptor has therefore been referred to as DRV2/GPR18 (Chiang et al., 2017), which is the terminology that will be used in this review. Also several other ligands activate DRV2/GPR18. These include endogenous ligands, such as $\mathrm{N}$-arachidonylglycine (NAGly), a metabolite of the endocannabinoid anandamide, synthetic ligands, e.g., abnormal-cannabidiol (Abn-CBD) as well as partial agonists of which O-1918 can be used as a pharmacological tool to inhibit DRV2/GPR18 signaling (Offertaler et al., 2003; Kohno et al., 2006). Depending on cell type and stimuli, the intracellular signal varies between increase and reduction in the cyclic AMP production (Kohno et al., 2006; McHugh et al., 2010,
2012; Chiang et al., 2015). The downstream effects thus vary from an increased capacity of macrophages to phagocyte debris and dead cells, a reduction in PMN infiltration (Chiang et al., 2015; Krohn et al., 2016), an implication in the homing and retention of $\mathrm{CD} 8 \alpha+\mathrm{T}$ cells in the intraepithelial lymphocyte compartment (Wang et al., 2014), and a modulation of microglial and endothelial migration (McHugh et al., 2010; Zhang et al., 2016).

\section{DRV2/GPR18 in Immune Cells}

DRV2/GPR18 has been detected in several immune cells with distinct functions. As mentioned above, it participates in the development and homing of CD8 $\alpha+$ lymphocytes (Figure 3) in the small intestine and mice deficient for GRP18 exhibit reduced numbers and migratory capacities of such cells into the duodenum (Wang et al., 2014). The believed mechanism of action involves a competition of GPR18 to activate the Gai G-coupled protein and induce migration (Wang et al., 2014). The development of the CD8 T cell compartment is of importance for tumor immunotherapy, treatment of inflammatory bowel diseases and viral infections. Yet the ligand responsible for this effect of DRV2/GPR18 needs to be determined with RvD2 being a top candidate (Wang et al., 2014).

In the mouse macrophage cell line RAW264.7, the activation of GPR18 via the endogenous ligand NAGly produced an approximately $70 \%$ decrease in the survival rate of macrophages. The effect is attributed to an increased apoptosis (Figure 3) and treatment with p38 MAPK inhibitors reversed the effect (Takenouchi et al., 2012). Therefore, in comparison to the beneficial property of DRV2/GPR18 described in CD8 cells, it appears that in this macrophage cell line, DRV2/GPR18 is deleterious and promotes an inflammatory status. Interestingly, an increased expression of GPR18 in macrophages polarized into the inflammatory M1 phenotype was observed, hence sustaining this pro-inflammatory effect (Takenouchi et al., 2012). However, while stimulation of DRV2/GPR18 by NAGly in mouse RAW macrophages increase apoptosis and caspase-3 expression, treatment of mouse bone marrow derived macrophages with $\mathrm{RvD} 2$ reduces the activation of the inflammasome when stimulated with LPS and ATP (Takenouchi et al., 2012; Lopategi et al., 2018). Indeed, macrophages treated with $\mathrm{RvD2}$ (Figure 3) has a reduced maturation of pro-IL-1 $\beta$ into mature and secreted IL-1 $\beta$ (Lopategi et al., 2018). This effect was blocked by the DRV2/GPR18 antagonist O-1918, supporting a receptormediated response. The action of RvD2 on macrophages was reproduced in a model of peritonitis where thioglycolaterecruited peritoneal macrophages were treated with LPS and palmitate. Addition of RvD2 to macrophages led to reduced IL-1 $\beta$ secretion and decreased caspase-1 activity (Lopategi et al., 2018). In a model of self-resolving peritonitis induced by zymosan-A activation of the inflammasome, RvD2 led to reduced oligomerization of ASC (a major component of the NLRP3 inflammasome), and a shift of macrophages toward pro-resolving M2 phenotype (Lopategi et al., 2018). Finally, in a model for sepsis induced by coeliac ligation puncture, the RvD2-DRV2/GPR18 pathway demonstrated protective effects by 
means of enhanced phosphorylation of ERK-1/2 in macrophages and an increase in phagocytosis (Chiang et al., 2017). The latter protection was absent in mice deficient for DRV2/GPR18 (Chiang et al., 2017). Therefore, it appears that depending on the ligand used to stimulate macrophages the effect is either pro or anti-inflammatory.

In addition to CD8 $\mathrm{T}$ cells and macrophages, DRV2/GPR18 is also present on polymorphonuclear neutrophils (PMN) (Chiang et al., 2015). The PMN is the first cell type to be recruited to injury/infectious site. Thus, investigating the effect of GPR18 activation on neutrophil recruitment is of particular interest. In a model of PMN chemotaxis toward IL-8, activation of DRV2/GPR18 by Abn-CBD reduced PMN recruitment (Figure 3) and co-incubation with the DRV2/GPR18 antagonist O-1918 restored the chemotaxis (Krohn et al., 2016). The results were also reproduced in a model of inflammation using flow chambers and endothelial cells treated with TNF $\alpha$ prior to assess the accumulation and transmigration of PMN treated with Abn-CBD and O-1918 (Krohn et al., 2016).

\section{DRV2/GPR18 in Ischemia/Reperfusion Injury}

DRV2/GPR18 engagement is also involved in the resolution of sterile inflammation. As an example, in the hind limb ischemia/reperfusion (I/R) procedure, which is characterized by PMN infiltration, activation of DRV2/GRP18 in WT mice could reduce the PMN infiltration in comparison to DRV2/GPR18 $\mathrm{KO}$ animals (Chiang et al., 2015). This result supports that the RvD2-DRV2/GPR18 axis implicated in the recruitment of PMN is also of relevance for cardiovascular inflammatory circuits. In a similar model, Zhang et al. (2016) found that $\mathrm{RvD} 2$ is generated in the bone marrow of animals during I/R procedure and subsequently detected in the ischemic skeletal muscle. Interestingly, RvD2 is also detected in biopsies of skeletal muscle of patients suffering peripheral artery disease (Zhang et al., 2016), supporting the pathophysiological implications of these experimental findings. Furthermore, mice deficient for DRV2/GPR18 displayed a defect in perfusion recovery, an effect due to reduction of endothelial cell migration. Indeed, endothelial cells also express DRV2/GPR18 (Zhang et al., 2016). When cells are treated with RvD2 they show increased migratory capacities, (Figure 3) which is abolished by both the DRV2/GPR18 antagonist O-1918 and the pretreatment with pertussis toxin. These results reveal that adding to the pro-resolving effect of DRV2/GPR18 on immune cells, the receptor participates in the healing of tissues through the activation of the $\mathrm{G} \alpha \mathrm{i}$ protein in endothelial cells. In a rat model of cerebral ischemia/reperfusion injury, Zuo et al. (2018) observed that the middle cerebral artery occlusion and reperfusion stimulus led to a significant decreased in RvD2 production and DRV2/GPR18 expression. Exogenous administration of RvD2 reversed the effect especially on neurons and brain microvascular endothelial cells (Zuo et al., 2018). These effects were partly mediated by increased ERK1/2 phosphorylation and the increased production of neuronal NOS
(nNOS) and endothelial NOS (eNOS). When pretreated with O-1918, the RvD2 function was partly abolished (Zuo et al., 2018).

\section{DRV2/GPR18 in Myocardial Function and Blood Pressure}

DRV2/GPR18 was recently found to be expressed in the rodent heart, notably in cardiomyocytes (Matouk et al., 2017). Chronic activation of the receptor by the ligand Abn-CBD reduces the blood pressure (BP), improves the left ventricular (LV) function and suppresses the sympathetic component of frequency (Matouk et al., 2017). These effects are accompanied by increased vascular levels of eNOS/NO and the circulating and cardiac levels of adiponectin (ADN) as well as phosphorylation of Akt and ERK1/2 (Figure 3) (Matouk et al., 2017). Likewise, DRV2/GRP18 activation has been associated with endotheliumdependent relaxations in resistance arteries through nitric oxide synthase activation (Al Suleimani and Al Mahruqi, 2017). Treatment with O-1918 abrogates the improvement in LV function and the reduction in BP, revokes the effect seen on NO, ADN, and Akt/ERK phosphorylation (Matouk et al., 2017), and blocks endothelium-dependent relaxations (Al Suleimani and Al Mahruqi, 2017), supporting a DRV2/GPR18-mediated response in those studies. Similar effects of DRV2/GPR18 activation were also observed in diabetic rats, where it ameliorated the diabetesinduced increase in vagal dominance and reduced oxidative stress of the myocardium, without impacting the diabetic-evoked cardiac hypertrophy and impaired control of glycaemia (Matouk et al., 2018). Activation of DRV2/GPR18 by NAGly also reduces the mean arterial blood pressure, but this effect is not impacted by the use of O-1918 (Al Suleimani and Al Mahruqi, 2017), hence indicating that this ligand in addition may signal through alternative pathways.

\section{ERV1/CHEMR23}

\section{ERV1/ChemR23 Ligands}

Initially classified as an orphan GPCR related to chemokine receptors (chemokine like receptor 1 or CMKLR1), ChemR23 was subsequently ligand paired with the chemotactic protein chemerin (Davenport et al., 2013). There are however several receptors for chemerin and a nomenclature of Chemerin1 receptor has also been proposed for this receptor (Kennedy and Davenport, 2018). When referring to RvE1 ligation with ChemR23, the receptor has been denoted ERV1 (Bäck et al., 2014; Lopez-Vicario et al., 2017; Sima et al., 2017; LagunaFernandez et al., 2018), and will in this review be referred to as ERV1/ChemR23.

The identification of ChemR23 as the high affinity RvE1 receptor (Bäck et al., 2014) was made through screening of the ability of RvE1 to inhibit $\mathrm{TNF} \alpha$-induced NF- $\kappa \mathrm{B}$ activation in HEK293 cells after transfection with candidate GPCRs (Arita et al., 2005) and subsequently confirmed by radioligand binding (Ohira et al., 2010) and $\beta$-arrestin assays (Kiwamoto et al., 2011). It should also be mentioned that RvE1 in addition binds to the human $\mathrm{BLT}_{1}$ receptor albeit with lower affinity (Arita et al., 2007). 


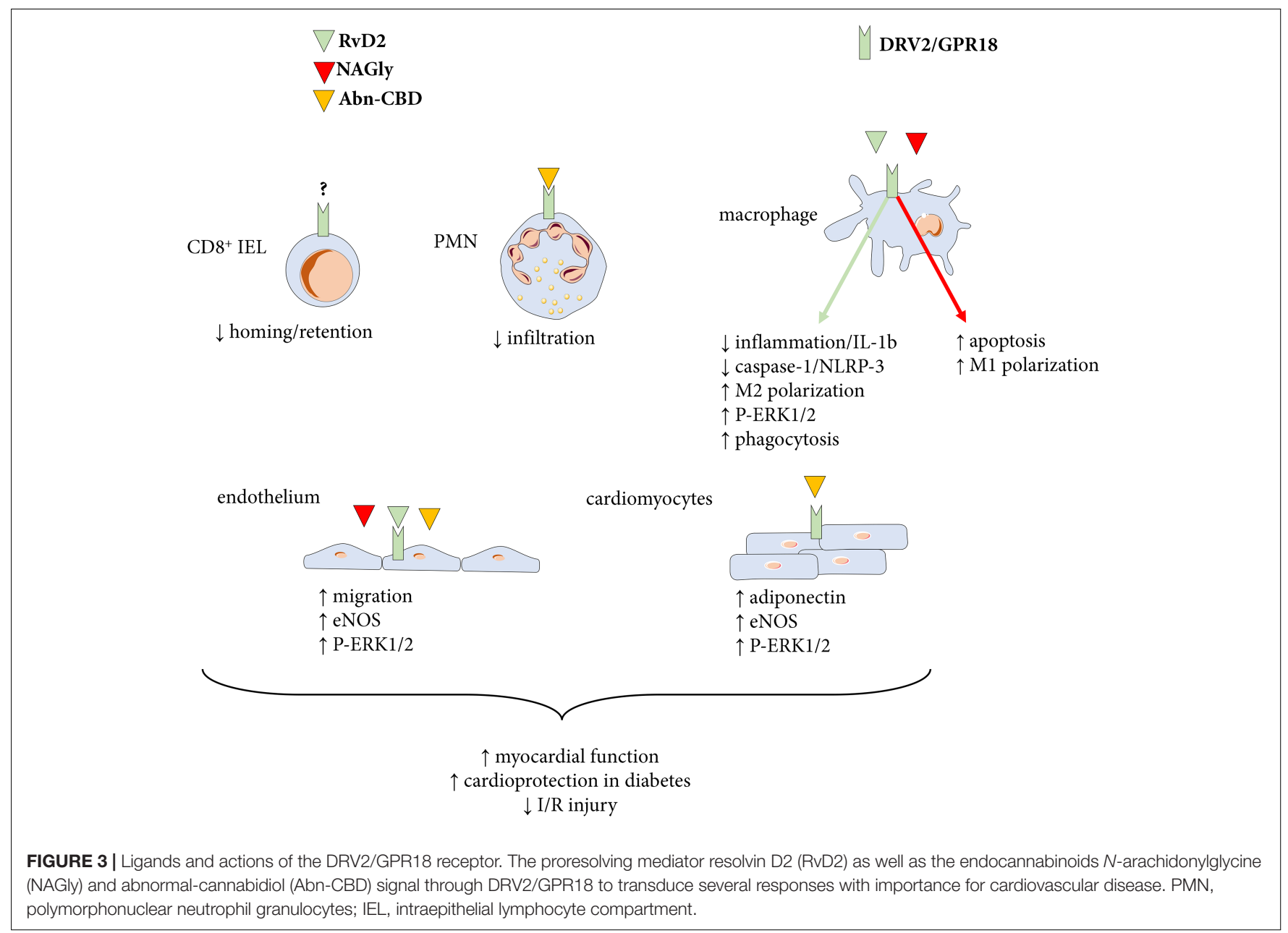

\section{ERV1/ChemR23 in Inflammation}

RvE1 limits neutrophil infiltration by means of promoting phagocytosis-induced neutrophil apoptosis and efferocytosis (El Kebir et al., 2012). It has also been demonstrated that murine macrophages derived from ERV1/ChemR23-deficient mice have an increased production of pro-inflammatory cytokines (Lopez-Vicario et al., 2017; Laguna-Fernandez et al., 2018), consistent with a predominantly anti-inflammatory action being transduced by this receptor. RvE1 enhances phagocytosis in human monocyte-derived macrophages, which is inhibited by an ERV1/ChemR23 antibody (Ohira et al., 2010) indicating that the pro-resolving effects of RvE1 are transduced through ERV1/ChemR23 (Figure 4). Recent findings in murine peritoneal macrophages have further strengthened this notion by replicating the enhancing effects of RvE1 on macrophage phagocytosis and also showing that those RvE1induced effects are absent in peritoneal macrophages derived from ERV1/ChemR23 knock-out mice (Laguna-Fernandez et al., 2018).

In analogy with the observations for ALX/FPR2 cited above, ERV1/ChemR23 may also possess a dual signaling depending on what agonist is activating the receptor. For example, whereas chemerin in general is considered to be a pro-inflammatory ligand for ERV1/ChemR23, certain chemerin-derived peptide show similar proresolving signaling patterns as RvE1 through this receptor (Kennedy and Davenport, 2018). Again, the balance between different available agonists may hence determine the dominant downstream ERV1/ChemR23 signaling. These dual effects are also observed in vivo. Transgenic overexpression of ChemR23 under the CD11b promoter enhances leukocyte clearance in a peritonitis model and increases RvE1-induced responses (Gao et al., 2013).

\section{ERV1/ChemR23 in Metabolic Disease}

A genetic variant of the ERV1/ChemR23 receptor was recently reported to protect patients with obesity from excessive inflammatory burden (Lopez-Vicario et al., 2017). The protective genotype was associated with increased ERV1/ChemR23 expression in adipose tissue and associated with lower local and systemic cytokine levels (Lopez-Vicario et al., 2017). These findings indicate that RvE1 signaling may also indirectly affect cardiovascular disease by means of altering metabolic factors.

\section{ERV1/ChemR23 in Myocardial Infarction}

Preconditioning with RvE1 reduces rodent myocardial ischemia/reperfusion (Keyes et al., 2010). Likewise, RvE1 


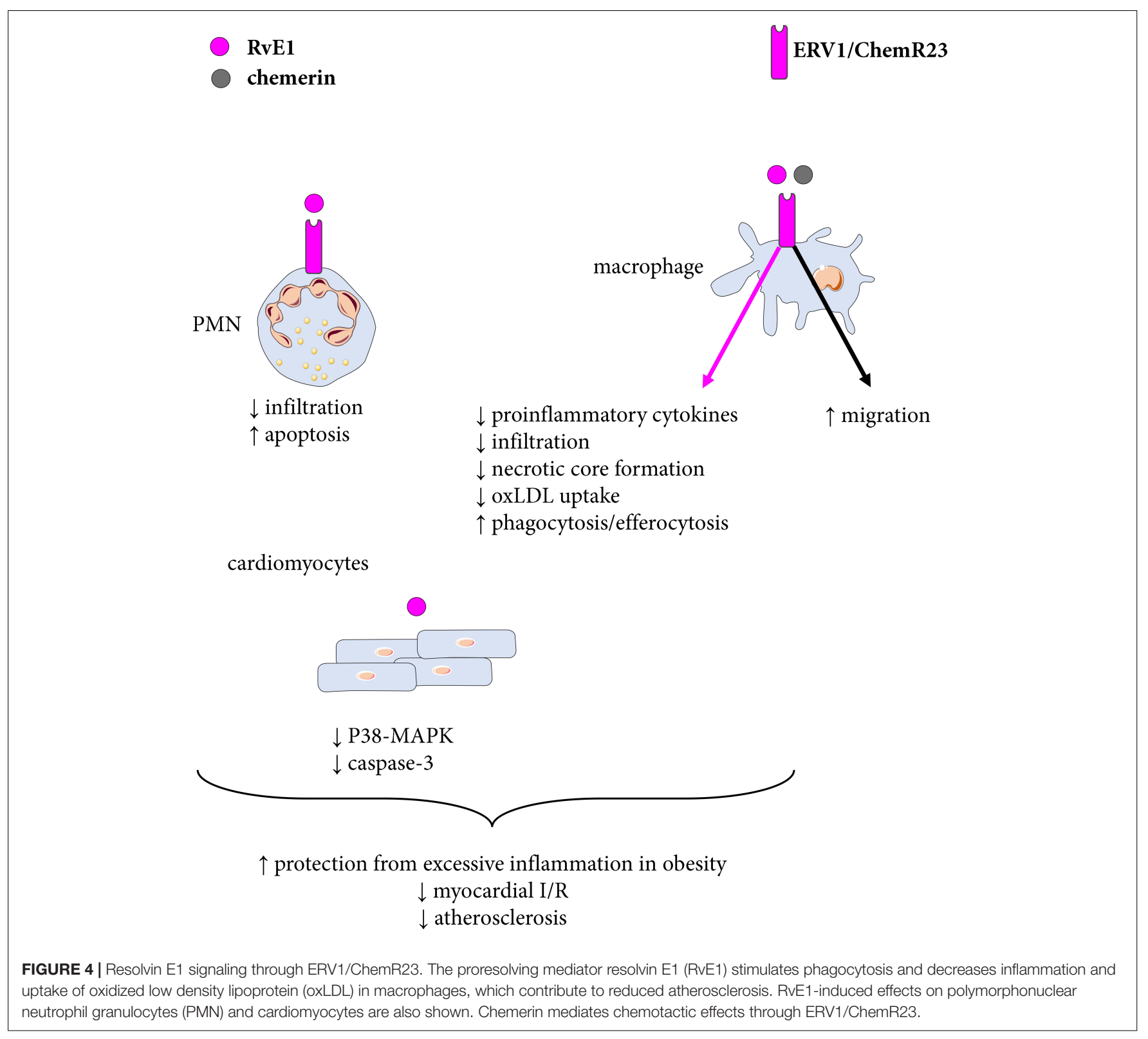

improves recovery of cardiac function when administered the first week after coronary ligation in mice, associated with reduced inflammatory cell infiltration in the myocardium, and decreased levels of inflammatory cytokines (Liu et al., 2018b). RvE1 also reduces the phosphorylation of p38 MAPK and decreases the levels of activated caspase- 3 in the H9c2 cell line, suggesting that RvE1-induced cardioprotection involves both suppression of inflammatory cell infiltration and direct effects on cardiomyocytes (Keyes et al., 2010). Although the receptor involved in RvE1-induced cardioprotection has not been examined, ERV1/ChemR23 is indeed expressed in rodent (Zhang et al., 2014) and murine cardiomyocytes (RodriguezPenas et al., 2015) further reinforcing possible direct effects of RvE1 transduced through cardiomyocytic ERV1/ChemR23 receptors.

\section{ERV1/ChemR23 in Atherosclerosis}

Exogenous administration of RvE1 reduces atherosclerosis (Hasturk et al., 2015; Salic et al., 2016) and intimal hyperplasia (Liu et al., 2018a) in different animal models, hence raising the notion of beneficial cardiovascular effects being transduced trough ERV1/ChemR23. This was recently determined by the generation of hyperlipidemic $\mathrm{ApoE}^{-/-}$mice lacking ERV1/ChemR23, which exhibit exacerbated atherosclerosis with larger lesions containing more macrophages compared with ERV1/ChemR23 expressing ApoE ${ }^{-/-}$littermates (LagunaFernandez et al., 2018). These findings were replicated after transfer of ERV1/ChemR23 deficient bone marrow to lethally irradiated $\mathrm{LDLR}^{-/-}$mice, supporting that the myeloid ERV1/ChemR23 expression transduced the beneficial effects in atherosclerosis. 
In human atherosclerotic lesions, ERV1/ChemR23 localizes to a subset of $\mathrm{CD} 68+$ macrophages residing in the proximity of the necrotic core (Laguna-Fernandez et al., 2018). Likewise, chimeric animals receiving ERV1/ChemR23-/- bone marrow exhibit a significant increase in necrotic core size (Laguna-Fernandez et al., 2018). Taken together, these observations suggest that in macrophages ERV1/ChemR23 may be directly involved in limiting necrotic core formation. Interestingly, stimulation of macrophages with RvE1 significantly decreases the uptake of oxidized LDL (oxLDL). Furthermore, peritoneal macrophages derived from ERV1/ChemR23 deficient mice exhibit a prolonged and continuous increase in oxLDL uptake as compared with wildtype mice. This also associated with a vascular upregulation of sortilin and other markers on lipid metabolism (Pirault et al., 2017). These recently described effects on lipid metabolism and oxLDL uptake add to already discussed functions in resolution biology by suggesting that proresolving signaling of RvE1 through ERV1/ChemR23 may directly decrease oxLDL uptake (Laguna-Fernandez et al., 2018). This would be expected to yield additional beneficial effects by decreasing necrotic core formation, limiting lipid-induced inflammatory activation and potentially reducing antigen presentation and activation of adaptive immune circuits (Laguna-Fernandez et al., 2018).

\section{ERV1/ChemR23: Therapeutic Options for Cardiovascular Disease}

In animal models, Resolvin E1 attenuates atherosclerosis in absence of cholesterol-lowering effects and on top of atorvastatin (Salic et al., 2016). Furthermore, statin-treated patients exhibit higher levels of ERV1/ChemR23 expression in carotid atherosclerotic lesions compared with those not under statin treatment (Laguna-Fernandez et al., 2018), supporting that stimulating proresolving ERV1/ChemR23 signaling (Figure 4) may have additive effects to current cardiovascular preventive treatment strategies.

\section{SUMMARY AND CONCLUSION}

In summary, four GPCRs have been identified to transduce the effects of the specialized pro-resolving mediators lipoxins and resolvins. This pro-resolving signaling involves an active termination of the immune response by means of, for example, increased neutrophil apoptosis and increased clearance through stimulating macrophage phagocytosis and efferocytosis.

The pro-resolving effects transduced through these GPCRs are however not limited to immune cells, as evidenced by their

\section{REFERENCES}

Akagi, D., Chen, M., Toy, R., Chatterjee, A., and Conte, M. S. (2015). Systemic delivery of proresolving lipid mediators resolvin D2 and maresin 1 attenuates intimal hyperplasia in mice. FASEB J. 29, 2504-2513. doi: 10.1096/fj.14-265363

Al Suleimani, Y. M., and Al Mahruqi, A. S. (2017). The endogenous lipid $\mathrm{N}$-arachidonoyl glycine is hypotensive and nitric oxide-cGMP-dependent vasorelaxant. Eur. J. Pharmacol. 794, 209-215. doi: 10.1016/j.ejphar.2016.11.040 expression also on structural cells of the vascular wall. In the latter context, stimulation of endothelial cell nitric oxide and migration, as well as limiting SMC migration and proliferation may participate to preserve the homeostasis of the vascular wall and to prevent, for example, endothelium dysfunction and intimal hyperplasia. Finally, direct effects on cardiomyocytes have been implicated in the cardioprotective effects of these mediators.

One possible therapeutic advantage of stimulating an active resolution of inflammation in comparison to anti-inflammation is to obtain an active termination of the immune reaction to prevent chronic inflammation, and at the same time avoiding immunosuppression. Since resolvins are formed from omega-3 polyunsaturated free fatty acids, optimizing resolvin formation may add to the beneficial effects of omega-3 fatty acids in chronic inflammation in general, and cardiovascular disease in particular. However, the indications for omega-3 supplementation in cardiovascular prevention today remains in debate.

Finally, this review emphasizes that not only proresolving mediators interact with the four GPCR addressed but also different ligands may transduce differential responses through the same receptors, which may in some cases even be opposite. Increasing the knowledge of the complex pharmacology of proresolving receptors and their multiple ligands will be crucial to approach specific therapeutic strategies to induce resolution of inflammation in cardiovascular disease.

\section{AUTHOR CONTRIBUTIONS}

All authors listed have made a substantial, direct and intellectual contribution to the work, and approved it for publication.

\section{FUNDING}

The authors are supported by the AGing Innovation \& Research (AGIR) Program on Normal and Pathological Aging (in partnership with the University Hospital of Nancy, the University of Lorraine, the Lorraine Region, the Urban Community of Nancy, and the operational program FEDER-FSE Lorraine et Massif des Vosges 2014-2020).

\section{ACKNOWLEDGMENTS}

The authors thank Dr. Simon N. Thornton for helpful advice on the manuscript.

Arita, M., Bianchini, F., Aliberti, J., Sher, A., Chiang, N., Hong, S., et al. (2005). Stereochemical assignment, antiinflammatory properties, and receptor for the omega-3 lipid mediator resolvin E1. J. Exp. Med. 201, 713-722. doi: 10.1084/ jem.20042031

Arita, M., Ohira, T., Sun, Y. P., Elangovan, S., Chiang, N., and Serhan, C. N. (2007). Resolvin E1 selectively interacts with leukotriene B4 receptor BLT1 and ChemR23 to regulate inflammation. J. Immunol. 178, 3912-3917. doi: 10.4049/ jimmunol.178.6.3912 
Arnardottir, H. H., Dalli, J., Norling, L. V., Colas, R. A., Perretti, M., and Serhan, C. N. (2016). Resolvin D3 is dysregulated in arthritis and reduces arthritic inflammation. J. Immunol. 197, 2362-2368. doi: 10.4049/jimmunol. 1502268

Bäck, M., Gasser, T. C., Michel, J. B., and Caligiuri, G. (2013). Biomechanical factors in the biology of aortic wall and aortic valve diseases. Cardiovasc. Res. 99, 232-241. doi: $10.1093 / \mathrm{cvr} / \mathrm{cvt} 040$

Bäck, M., and Hansson, G. K. (2015). Anti-inflammatory therapies for atherosclerosis. Nat. Rev. Cardiol. 12, 199-211. doi: 10.1038/nrcardio. 2015.5

Bäck, M., Powell, W. S., Dahlén, S. E., Drazen, J. M., Evans, J. F., Serhan, C. N., et al. (2014). Update on leukotriene, lipoxin and oxoeicosanoid receptors: IUPHAR review 7. Br. J. Pharmacol. 171, 3551-3574. doi: 10.1111/bph.12665

Bäck, M., Weber, C., and Lutgens, E. (2015). Regulation of atherosclerotic plaque inflammation. J. Intern. Med. 278, 462-482. doi: 10.1111/joim.12367

Barnig, C., Cernadas, M., Dutile, S., Liu, X., Perrella, M. A., Kazani, S., et al. (2013). Lipoxin A4 regulates natural killer cell and type 2 innate lymphoid cell activation in asthma. Sci. Transl. Med. 5:174ra26. doi: 10.1126/scitranslmed. 3004812

Brancaleone, V., Gobbetti, T., Cenac, N., le Faouder, P., Colom, B., Flower, R. J., et al. (2013). A vasculo-protective circuit centered on lipoxin A4 and aspirintriggered 15-epi-lipoxin A4 operative in murine microcirculation. Blood 122, 608-617. doi: 10.1182/blood-2013-04-496661

Brezinski, D. A., Nesto, R. W., and Serhan, C. N. (1992). Angioplasty triggers intracoronary leukotrienes and lipoxin A4. Impact of aspirin therapy. Circulation 86, 56-63. doi: 10.1161/01.CIR.86.1.56

Cash, J. L., Norling, L. V., and Perretti, M. (2014). Resolution of inflammation: targeting GPCRs that interact with lipids and peptides. Drug Discov. Today 19, 1186-1192. doi: 10.1016/j.drudis.2014.06.023

Chattopadhyay, R., Raghavan, S., and Rao, G. N. (2017). Resolvin D1 via prevention of ROS-mediated SHP2 inactivation protects endothelial adherens junction integrity and barrier function. Redox Biol. 12, 438-455. doi: 10.1016/j. redox.2017.02.023

Chiang, N., Dalli, J., Colas, R. A., and Serhan, C. N. (2015). Identification of resolvin D2 receptor mediating resolution of infections and organ protection. J. Exp. Med. 212, 1203-1217. doi: 10.1084/jem.20150225

Chiang, N., de la Rosa, X., Libreros, S., and Serhan, C. N. (2017). Novel resolvin D2 receptor axis in infectious inflammation. J. Immunol. 198, 842-851. doi: 10.4049/jimmunol.1601650

Chiang, N., Fierro, I. M., Gronert, K., and Serhan, C. N. (2000). Activation of lipoxin $\mathrm{A}(4)$ receptors by aspirin-triggered lipoxins and select peptides evokes ligand-specific responses in inflammation. J. Exp. Med. 191, 1197-1208. doi: 10.1084/jem.191.7.1197

Chiang, N., Fredman, G., Backhed, F., Oh, S. F., Vickery, T., Schmidt, B. A., et al. (2012). Infection regulates pro-resolving mediators that lower antibiotic requirements. Nature 484, 524-528. doi: 10.1038/nature 11042

Chiang, N., Gronert, K., Clish, C. B., O’Brien, J. A., Freeman, M. W., and Serhan, C. N. (1999). Leukotriene B4 receptor transgenic mice reveal novel protective roles for lipoxins and aspirin-triggered lipoxins in reperfusion. J. Clin. Invest. 104, 309-316. doi: 10.1172/JCI7016

Chiang, N., Serhan, C. N., Dahlén, S. E., Drazen, J. M., Hay, D. W., Rovati, G. E., et al. (2006). The lipoxin receptor ALX: potent ligand-specific and stereoselective actions in vivo. Pharmacol. Rev. 58, 463-487. doi: 10.1124/pr. 58.3.4

Chiurchiu, V., Leuti, A., Dalli, J., Jacobsson, A., Battistini, L., Maccarrone, M., et al. (2016). Proresolving lipid mediators resolvin D1, resolvin D2, and maresin 1 are critical in modulating $\mathrm{T}$ cell responses. Sci. Transl. Med. 8:353ra111. doi: $10.1126 /$ scitranslmed.aaf 7483

Dalli, J., Consalvo, A. P., Ray, V., Di Filippo, C., D’Amico, M., Mehta, N., et al. (2013a). Proresolving and tissue-protective actions of annexin A1based cleavage-resistant peptides are mediated by formyl peptide receptor 2/lipoxin A4 receptor. J. Immunol. 190, 6478-6487. doi: 10.4049/jimmunol. 1203000

Dalli, J., Winkler, J. W., Colas, R. A., Arnardottir, H., Cheng, C. Y., Chiang, N., et al. (2013b). Resolvin D3 and aspirin-triggered resolvin D3 are potent immunoresolvents. Chem. Biol. 20, 188-201. doi: 10.1016/j.chembiol.2012. 11.010
Davenport, A. P., Alexander, S. P., Sharman, J. L., Pawson, A. J., Benson, H. E., Monaghan, A. E., et al. (2013). International union of basic and clinical pharmacology. LXXXVIII. G protein-coupled receptor list: recommendations for new pairings with cognate ligands. Pharmacol. Rev. 65, 967-986. doi: 10. 1124/pr.112.007179

Doring, Y., Drechsler, M., Wantha, S., Kemmerich, K., Lievens, D., Vijayan, S., et al. (2012). Lack of neutrophil-derived CRAMP reduces atherosclerosis in mice. Circ. Res. 110, 1052-1056. doi: 10.1161/CIRCRESAHA.112.265868

Drechsler, M., de Jong, R., Rossaint, J., Viola, J. R., Leoni, G., Wang, J. M., et al. (2015). Annexin A1 counteracts chemokine-induced arterial myeloid cell recruitment. Circ. Res. 116, 827-835. doi: 10.1161/CIRCRESAHA.116. 305825

Edfeldt, K., Agerberth, B., Rottenberg, M. E., Gudmundsson, G. H., Wang, X. B., Mandal, K., et al. (2006). Involvement of the antimicrobial peptide LL-37 in human atherosclerosis. Arterioscler. Thromb. Vasc. Biol. 26, 1551-1557. doi: 10.1161/01.ATV.0000223901.08459.57

El Kebir, D., Gjorstrup, P., and Filep, J. G. (2012). Resolvin E1 promotes phagocytosis-induced neutrophil apoptosis and accelerates resolution of pulmonary inflammation. Proc. Natl. Acad. Sci. U.S.A. 109, 14983-14988. doi: 10.1073/pnas.1206641109

Fredman, G., Kamaly, N., Spolitu, S., Milton, J., Ghorpade, D., Chiasson, R., et al. (2015). Targeted nanoparticles containing the proresolving peptide Ac226 protect against advanced atherosclerosis in hypercholesterolemic mice. Sci. Transl. Med. 7:275ra20. doi: 10.1126/scitranslmed.aaa1065

Fredman, G., Ozcan, L., Spolitu, S., Hellmann, J., Spite, M., Backs, J., et al. (2014). Resolvin D1 limits 5-lipoxygenase nuclear localization and leukotriene B4 synthesis by inhibiting a calcium-activated kinase pathway. Proc. Natl. Acad. Sci. U.S.A. 111, 14530-14535. doi: 10.1073/pnas.1410851111

Fredman, G., and Tabas, I. (2017). Boosting inflammation resolution in atherosclerosis: the next frontier for therapy. Am. J. Pathol. 187, 1211-1221. doi: 10.1016/j.ajpath.2017.01.018

Gantz, I., Muraoka, A., Yang, Y. K., Samuelson, L. C., Zimmerman, E. M., Cook, H., et al. (1997). Cloning and chromosomal localization of a gene (GPR18) encoding a novel seven transmembrane receptor highly expressed in spleen and testis. Genomics 42, 462-466. doi: 10.1006/geno.1997.4752

Gao, L., Faibish, D., Fredman, G., Herrera, B. S., Chiang, N., Serhan, C. N., et al. (2013). Resolvin E1 and chemokine-like receptor 1 mediate bone preservation. J. Immunol. 190, 689-694. doi: 10.4049/jimmunol.1103688

Gronert, K., Gewirtz, A., Madara, J. L., and Serhan, C. N. (1998). Identification of a human enterocyte lipoxin A4 receptor that is regulated by interleukin (IL)-13 and interferon gamma and inhibits tumor necrosis factor alpha-induced IL-8 release. J. Exp. Med. 187, 1285-1294. doi: 10.1084/jem.187.8.1285

Hachicha, M., Pouliot, M., Petasis, N. A., and Serhan, C. N. (1999). Lipoxin (LX)A4 and aspirin-triggered 15-epi-LXA4 inhibit tumor necrosis factor 1alpha-initiated neutrophil responses and trafficking: regulators of a cytokinechemokine axis. J. Exp. Med. 189, 1923-1930. doi: 10.1084/jem.189.12.1923

Halade, G. V., Kain, V., and Serhan, C. N. (2018). Immune responsive resolvin D1 programs myocardial infarction-induced cardiorenal syndrome in heart failure. FASEB J. 32, 3717-3729. doi: 10.1096/fj.201701173RR

Hasturk, H., Abdallah, R., Kantarci, A., Nguyen, D., Giordano, N., Hamilton, J., et al. (2015). Resolvin E1 (RvE1) attenuates atherosclerotic plaque formation in diet and inflammation-induced atherogenesis. Arterioscler. Thromb. Vasc. Biol. 35, 1123-1133. doi: 10.1161/ATVBAHA.115.30 5324

Hayhoe, R. P., Kamal, A. M., Solito, E., Flower, R. J., Cooper, D., and Perretti, M. (2006). Annexin 1 and its bioactive peptide inhibit neutrophil-endothelium interactions under flow: indication of distinct receptor involvement. Blood 107, 2123-2130. doi: 10.4049/jimmunol.1502268

Ho, K. J., Spite, M., Owens, C. D., Lancero, H., Kroemer, A. H., Pande, R., et al. (2010). Aspirin-triggered lipoxin and resolvin E1 modulate vascular smooth muscle phenotype and correlate with peripheral atherosclerosis. Am. J. Pathol. 177, 2116-2123. doi: 10.2353/ajpath.2010.091082

Houard, X., Ollivier, V., Louedec, L., Michel, J. B., and Bäck, M. (2009a). Differential inflammatory activity across human abdominal aortic aneurysms reveals neutrophil-derived leukotriene B4 as a major chemotactic factor released from the intraluminal thrombus. FASEB J. 23, 1376-1383. doi: 10.1096/fj.08116202 
Houard, X., Touat, Z., Ollivier, V., Louedec, L., Philippe, M., Sebbag, U., et al. (2009b). Mediators of neutrophil recruitment in human abdominal aortic aneurysms. Cardiovasc. Res. 82, 532-541. doi: 10.1093/cvr/cvp048

Kain, V., Ingle, K. A., Colas, R. A., Dalli, J., Prabhu, S. D., Serhan, C. N., et al. (2015). Resolvin D1 activates the inflammation resolving response at splenic and ventricular site following myocardial infarction leading to improved ventricular function. J. Mol. Cell. Cardiol. 84, 24-35. doi: 10.1016/j.yjmcc.2015.04.003

Kain, V., Prabhu, S. D., and Halade, G. V. (2014). Inflammation revisited: inflammation versus resolution of inflammation following myocardial infarction. Basic Res. Cardiol. 109:444. doi: 10.1007/s00395-0140444-7

Karagiannis, G. S., Weile, J., Bader, G. D., and Minta, J. (2013). Integrative pathway dissection of molecular mechanisms of moxLDL-induced vascular smooth muscle phenotype transformation. BMC Cardiovasc. Disord. 13:4. doi: 10.1186/ 1471-2261-13-4

Kennedy, A. J., and Davenport, A. P. (2018). International union of basic and clinical pharmacology CIII: chemerin receptors CMKLR1 (Chemerin1) and GPR1 (Chemerin2) nomenclature, pharmacology, and function. Pharmacol. Rev. 70, 174-196. doi: 10.1124/pr.116.013177

Keyes, K. T., Ye, Y., Lin, Y., Zhang, C., Perez-Polo, J. R., Gjorstrup, P., et al. (2010). Resolvin E1 protects the rat heart against reperfusion injury. Am. J. Physiol. Heart Circ. Physiol. 299, H153-H164. doi: 10.1152/ajpheart.01057.2009

Kiwamoto, T., Ishii, Y., Morishima, Y., Yoh, K., Kikuchi, N., Haraguchi, N., et al. (2011). Blockade of cysteinyl leukotriene-1 receptors suppresses airway remodelling in mice overexpressing GATA-3. Clin. Exp. Allergy 41, 116-128. doi: 10.1111/j.1365-2222.2010.03571.x

Kohno, M., Hasegawa, H., Inoue, A., Muraoka, M., Miyazaki, T., Oka, K., et al. (2006). Identification of $\mathrm{N}$-arachidonylglycine as the endogenous ligand for orphan G-protein-coupled receptor GPR18. Biochem. Biophys. Res. Commun. 347, 827-832. doi: 10.1084/jem.20150225

Krishnamoorthy, S., Recchiuti, A., Chiang, N., Fredman, G., and Serhan, C. N. (2012). Resolvin D1 receptor stereoselectivity and regulation of inflammation and proresolving microRNAs. Am. J. Pathol. 180, 2018-2027. doi: 10.1016/j. ajpath.2012.01.028

Krishnamoorthy, S., Recchiuti, A., Chiang, N., Yacoubian, S., Lee, C. H., Yang, R., et al. (2010). Resolvin D1 binds human phagocytes with evidence for proresolving receptors. Proc. Natl. Acad. Sci. U.S.A. 107, 1660-1665. doi: 10. 1073/pnas.0907342107

Krohn, R. M., Parsons, S. A., Fichna, J., Patel, K. D., Yates, R. M., Sharkey, K. A., et al. (2016). Abnormal cannabidiol attenuates experimental colitis in mice, promotes wound healing and inhibits neutrophil recruitment. J. Inflamm. 13:21. doi: 10.1186/s12950-016-0129-0

Laguna-Fernandez, A., Checa, A., Carracedo, M., Artiach, G., Petri, M. H., Baumgartner, R., et al. (2018). ERV1/ChemR23 signaling protects from atherosclerosis by modifying oxLDL uptake and phagocytosis in macrophages. Circulatio doi: 10.1161/CIRCULATIONAHA.117.032801 [Epub ahead of print].

Levy, B. D., Clish, C. B., Schmidt, B., Gronert, K., and Serhan, C. N. (2001). Lipid mediator class switching during acute inflammation: signals in resolution. Nat. Immunol. 2, 612-619. doi: 10.1124/pr.58.3.4

Liu, G., Gong, Y., Zhang, R., Piao, L., Li, X., Liu, Q., et al. (2018a). Resolvin $\mathrm{E} 1$ attenuates injury-induced vascular neointimal formation by inhibition of inflammatory responses and vascular smooth muscle cell migration. FASEB J. 32, 5413-5425. doi: 10.1096/fj.201800173R

Liu, G., Liu, Q., Shen, Y., Kong, D., Gong, Y., Tao, B., et al. (2018b). Early treatment with resolvin E1 facilitates myocardial recovery from ischaemia in mice. Br. J. Pharmacol. 175, 1205-1216. doi: 10.1111/bph. 14041

Lopategi, A., Flores-Costa, R., Rius, B., Lopez-Vicario, C., Alcaraz-Quiles, J., Titos, E., et al. (2018). Frontline science: specialized proresolving lipid mediators inhibit the priming and activation of the macrophage NLRP3 inflammasome. J. Leukoc. Biol. doi: 10.1002/JLB.3HI0517-206RR [Epub ahead of print].

Lopez-Vicario, C., Rius, B., Alcaraz-Quiles, J., Gonzalez-Periz, A., MartinezPuchol, A. I., Casulleras, M., et al. (2017). Association of a variant in the gene encoding for ERV1/ChemR23 with reduced inflammation in visceral adipose tissue from morbidly obese individuals. Sci. Rep. 7:15724. doi: 10.1038/s41598017-15951-z
Maderna, P., Cottell, D. C., Toivonen, T., Dufton, N., Dalli, J., Perretti, M., et al. (2010). FPR2/ALX receptor expression and internalization are critical for lipoxin A4 and annexin-derived peptide-stimulated phagocytosis. FASEB J. 24, 4240-4249. doi: 10.1096/fj.10-159913

Matouk, A. I., Taye, A., El-Moselhy, M. A., Heeba, G. H., and Abdel-Rahman, A. A. (2017). The effect of chronic activation of the novel endocannabinoid receptor GPR18 on myocardial function and blood pressure in conscious rats. J. Cardiovasc. Pharmacol. 69, 23-33. doi: 10.1097/FJC.0000000000000438

Matouk, A. I., Taye, A., El-Moselhy, M. A., Heeba, G. H., and Abdel-Rahman, A. A. (2018). Abnormal cannabidiol confers cardioprotection in diabetic rats independent of glycemic control. Eur. J. Pharmacol. 820, 256-264. doi: 10.1016/ j.ejphar.2017.12.039

McHugh, D., Hu, S. S., Rimmerman, N., Juknat, A., Vogel, Z., Walker, J. M., et al. (2010). N-arachidonoyl glycine, an abundant endogenous lipid, potently drives directed cellular migration through GPR18, the putative abnormal cannabidiol receptor. BMC Neurosci. 11:44. doi: 10.1186/1471-2202-11-44

McHugh, D., Page, J., Dunn, E., and Bradshaw, H. B. (2012). Delta(9) Tetrahydrocannabinol and $\mathrm{N}$-arachidonyl glycine are full agonists at GPR18 receptors and induce migration in human endometrial HEC-1B cells. Br. J. Pharmacol. 165, 2414-2424. doi: 10.1111/j.1476-5381.2011.01497.x

Michel, J. B., Martin-Ventura, J. L., Egido, J., Sakalihasan, N., Treska, V., Lindholt, J., et al. (2011). Novel aspects of the pathogenesis of aneurysms of the abdominal aorta in humans. Cardiovasc. Res. 90, 18-27. doi: 10.1093/cvr/ cvq337

Miyahara, T., Runge, S., Chatterjee, A., Chen, M., Mottola, G., Fitzgerald, J. M., et al. (2013). D-series resolvin attenuates vascular smooth muscle cell activation and neointimal hyperplasia following vascular injury. FASEB J. 27, 2220-2232. doi: 10.1096/fj.12-225615

Mottola, G., Chatterjee, A., Wu, B., Chen, M., and Conte, M. S. (2017). Aspirintriggered resolvin D1 attenuates PDGF-induced vascular smooth muscle cell migration via the cyclic adenosine monophosphate/protein kinase A (cAMP/PKA) pathway. PLoS One 12:e0174936. doi: 10.1371/journal.pone. 0174936

Offertaler, L., Mo, F. M., Batkai, S., Liu, J., Begg, M., Razdan, R. K., et al. (2003). Selective ligands and cellular effectors of a $\mathrm{G}$ protein-coupled endothelial cannabinoid receptor. Mol. Pharmacol. 63, 699-705. doi: 10.4049/jimmunol. 1103688

Ohira, T., Arita, M., Omori, K., Recchiuti, A., Van Dyke, T. E., and Serhan, C. N. (2010). Resolvin E1 receptor activation signals phosphorylation and phagocytosis. J. Biol. Chem. 285, 3451-3461. doi: 10.1074/jbc.M109.04 4131

Orr, S. K., Colas, R. A., Dalli, J., Chiang, N., and Serhan, C. N. (2015). Proresolving actions of a new resolvin D1 analog mimetic qualifies as an immunoresolvent. Am. J. Physiol. Lung. Cell. Mol. Physiol. 308, L904-L911. doi: 10.1152/ajplung. 00370.2014

Perretti, M., Leroy, X., Bland, E. J., and Montero-Melendez, T. (2015). Resolution pharmacology: opportunities for therapeutic innovation in inflammation. Trends Pharmacol. Sci. 36, 737-755. doi: 10.1016/j.tips.2015. 07.007

Petri, M. H., Laguna-Fernandez, A., Arnardottir, H., Wheelock, C. E., Perretti, M., Hansson, G. K., et al. (2017). Aspirin-triggered lipoxin A4 inhibits atherosclerosis progression in apolipoprotein E-/- mice. Br. J. Pharmacol. 174, 4043-4054. doi: 10.1111/bph.13707

Petri, M. H., Laguna-Fernandez, A., Gonzalez-Diez, M., Paulsson-Berne, G., Hansson, G. K., and Bäck, M. (2015a). The role of the FPR2/ALX receptor in atherosclerosis development and plaque stability. Cardiovasc. Res. 105, 65-74. doi: $10.1093 / \mathrm{cvr} / \mathrm{cvu} 224$

Petri, M. H., Laguna-Fernandez, A., Tseng, C. N., Hedin, U., Perretti, M., and Bäck, M. (2015b). Aspirin-triggered 15-epi-lipoxin A(4) signals through FPR2/ALX in vascular smooth muscle cells and protects against intimal hyperplasia after carotid ligation. Int. J. Cardiol. 179, 370-372. doi: 10.2353/ ajpath.2010.091082

Petri, M. H., Thul, S., Andonova, T., Lindquist-Liljeqvist, M., Jin, H., Skenteris, N.T., et al. (2018). Resolution of inflammation through the lipoxin and ALX/FPR2 receptor pathway protects against abdominal aortic aneurysms. JACCBasic Transl. Sci. (in press). doi: 10.1016/j.jacbts.2018.08.005

Petri, M. H., Thul, S., Ovchinnikova, O., and Bäck, M. (2015c). Differential regulation of monocytic expression of leukotriene and lipoxin receptors. 
Prostaglandins Other Lipid Mediat. 121(Pt A), 138-143. doi: 10.1016/j. prostaglandins.2015.07.005

Pillai, P. S., Leeson, S., Porter, T. F., Owens, C. D., Kim, J. M., Conte, M. S., et al. (2012). Chemical mediators of inflammation and resolution in post-operative abdominal aortic aneurysm patients. Inflammation 35, 98-113. doi: 10.1007/ s10753-011-9294-8

Pirault, J., Polyzos, K. A., Petri, M. H., Ketelhuth, D. F. J., Bäck, M., and Hansson, G. K. (2017). The inflammatory cytokine interferon-gamma inhibits sortilin1 expression in hepatocytes via the JAK/STAT pathway. Eur. J. Immunol. 47, 1918-1924. doi: 10.1002/eji.201646768

Pope, N. H., Salmon, M., Davis, J. P., Chatterjee, A., Su, G., Conte, M. S., et al. (2016). D-series resolvins inhibit murine abdominal aortic aneurysm formation and increase M2 macrophage polarization. FASEB J. 30, 4192-4201. doi: 10. 1186/1471-2261-13-4

Recchiuti, A., Krishnamoorthy, S., Fredman, G., Chiang, N., and Serhan, C. N. (2011). MicroRNAs in resolution of acute inflammation: identification of novel resolvin D1-miRNA circuits. FASEB J. 25, 544-560. doi: 10.1096/fj.10- 169599

Recchiuti, A., and Serhan, C. N. (2012). Pro-resolving lipid mediators (SPMs) and their actions in regulating miRNA in novel resolution circuits in inflammation. Front. Immunol. 3:298. doi: 10.3389/fimmu.2012.00298

Rodriguez-Penas, D., Feijoo-Bandin, S., Garcia-Rua, V., Mosquera-Leal, A., Duran, D., Varela, A., et al. (2015). The adipokine chemerin induces apoptosis in cardiomyocytes. Cell. Physiol. Biochem. 37, 176-192. doi: 10.1159/000430343

Salic, K., Morrison, M. C., Verschuren, L., Wielinga, P. Y., Wu, L., Kleemann, R., et al. (2016). Resolvin E1 attenuates atherosclerosis in absence of cholesterollowering effects and on top of atorvastatin. Atherosclerosis 250, 158-165. doi: 10.1016/j.atherosclerosis.2016.05.001

Samuelson, L. C., Swanberg, L. J., and Gantz, I. (1996). Mapping of the novel $\mathrm{G}$ protein-coupled receptor Gpr18 to distal mouse chromosome 14. Mamm. Genome 7, 920-921. doi: 10.1016/j.ajpath.2012.01.028

Schmid, M., Gemperle, C., Rimann, N., and Hersberger, M. (2016). Resolvin D1 polarizes primary human macrophages toward a proresolution phenotype through GPR32. J. Immunol. 196, 3429-3437. doi: 10.4049/jimmunol.1501701

Serhan, C. N. (2014). Pro-resolving lipid mediators are leads for resolution physiology. Nature 510, 92-101. doi: 10.1038/nature13479

Sima, C., Montero, E., Nguyen, D., Freire, M., Norris, P., Serhan, C. N., et al. (2017). ERV1 overexpression in myeloid cells protects against high fat diet induced obesity and glucose intolerance. Sci. Rep. 7:12848. doi: 10.1038/s41598-01713185-7

Smith, H. K., Gil, C. D., Oliani, S. M., and Gavins, F. N. (2015). Targeting formyl peptide receptor 2 reduces leukocyte-endothelial interactions in a murine model of stroke. FASEB J. 29, 2161-2171. doi: 10.1096/fj.14-263160

Takenouchi, R., Inoue, K., Kambe, Y., and Miyata, A. (2012). N-arachidonoyl glycine induces macrophage apoptosis via GPR18. Biochem. Biophys. Res. Commun. 418, 366-371. doi: 10.1016/j.bbrc.2012.01.027

Umeda, H., Aikawa, M., and Libby, P. (2011). Liberation of desmosine and isodesmosine as amino acids from insoluble elastin by elastolytic proteases.
Biochem. Biophys. Res. Commun. 411, 281-286. doi: 10.1016/j.bbrc.2011. 06.124

van Gils, J. M., Derby, M. C., Fernandes, L. R., Ramkhelawon, B., Ray, T. D., Rayner, K. J., et al. (2012). The neuroimmune guidance cue netrin-1 promotes atherosclerosis by inhibiting the emigration of macrophages from plaques. Nat. Immunol. 13, 136-143. doi: 10.1038/ni.2205

Vassilatis, D. K., Hohmann, J. G., Zeng, H., Li, F., Ranchalis, J. E., Mortrud, M. T., et al. (2003). The G protein-coupled receptor repertoires of human and mouse. Proc. Natl. Acad. Sci. U.S.A. 100, 4903-4908. doi: 10.1038/s41598-01715951-z

Vital, S. A., Becker, F., Holloway, P. M., Russell, J., Perretti, M., Granger, D. N., et al. (2016). Formyl-peptide receptor 2/3/lipoxin A4 receptor regulates neutrophil-platelet aggregation and attenuates cerebral inflammation: impact for therapy in cardiovascular disease. Circulation 133, 2169-2179. doi: 10.1161/ CIRCULATIONAHA.115.020633

Wadey, K., Lopes, J., Bendeck, M., and George, S. (2018). Role of smooth muscle cells in coronary artery bypass grafting failure. Cardiovasc. Res. 114, 601-610. doi: $10.1093 / \mathrm{cvr} / \mathrm{cvy} 021$

Wang, X., Sumida, H., and Cyster, J. G. (2014). GPR18 is required for a normal CD8alphaalpha intestinal intraepithelial lymphocyte compartment. J. Exp. Med. 211, 2351-2359. doi: 10.1084/jem.20140646

Ye, R. D., Boulay, F., Wang, J. M., Dahlgren, C., Gerard, C., Parmentier, M., et al. (2009). International union of basic and clinical pharmacology. LXXIII. Nomenclature for the formyl peptide receptor (FPR) family. Pharmacol. Rev. 61, 119-161. doi: 10.1124/pr.109.001578

Zhang, M. J., Sansbury, B. E., Hellmann, J., Baker, J. F., Guo, L., Parmer, C. M., et al. (2016). Resolvin D2 enhances postischemic revascularization while resolving inflammation. Circulation 134, 666-680. doi: 10.1161/CIRCULATIONAHA. 116.021894

Zhang, R., Liu, S., Guo, B., Chang, L., and Li, Y. (2014). Chemerin induces insulin resistance in rat cardiomyocytes in part through the ERK1/2 signaling pathway. Pharmacology 94, 259-264. doi: 10.1159/0003 69171

Zuo, G., Zhang, D., Mu, R., Shen, H., Li, X., Wang, Z., et al. (2018). Resolvin D2 protects against cerebral ischemia/reperfusion injury in rats. Mol. Brain 11:9. doi: 10.1186/s13041-018-0351-1

Conflict of Interest Statement: The authors declare that the research was conducted in the absence of any commercial or financial relationships that could be construed as a potential conflict of interest.

Copyright (c) 2018 Pirault and Bäck. This is an open-access article distributed under the terms of the Creative Commons Attribution License (CC BY). The use, distribution or reproduction in other forums is permitted, provided the original author(s) and the copyright owner(s) are credited and that the original publication in this journal is cited, in accordance with accepted academic practice. No use, distribution or reproduction is permitted which does not comply with these terms. 